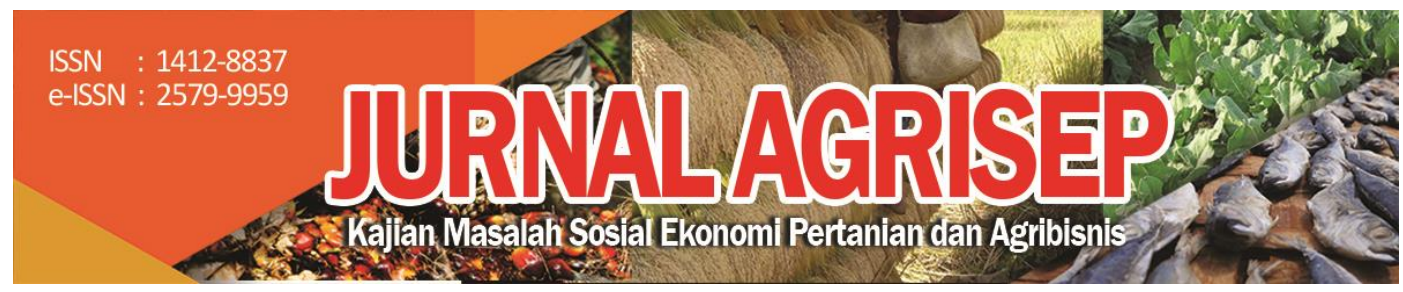

DOI: 10.31186/jagrisep.20.1.69-80

\title{
ANALISIS SWOT TENTANG STRATEGI PEMASARAN AGRIBISNIS DI PULAU SETOKOK (STUDI KASUS KOMODITAS SEMANGKA)
}

\section{SWOT Analysis Of Agribusiness Marketing Strategies In Setokok Island (Case Study: Watermelon Comodities)}

\author{
Fandy Bestario Harlan ${ }_{1}$; Adhitomo Wirawan'2); Nur Alifia Maulida3) \\ 1,2,3)Jurusan Manajemen Bisnis, Politeknik Negeri Batam \\ Email: fandybestario@polibatam.ac.id
}

\begin{abstract}
This study aimed to analyze the concept of the most appropriate marketing strategic to be applied to the Agribisnis Semangka Batam of Kepulauan Setokok Batam. This research uses descriptive analysis with qualitative approach. The data sources used in this analysis are primary data from respondents and secondary data from company documents. The technical analysis of the data used is carried out through SWOT analysis. The results show that the position Agribisnis Semangka in unit I using the SWOT chart indicates that the outcome of the analysis is positive, and the correct strategy at this position is the "growth strategy". Then the appropriate strategic alternatives for Agribisnis Semangka using S-O strategy (Strength-Opportunity) by maintaining fruit quality and service to consumers, utilizing distribution channels, increasing promotion on each type of product utilizing broad market Opportunities and maintaining prices that can compete in the market
\end{abstract}

Keywords: SWOT Analysis, Marketing Strategy, Agribusiness

\section{ABSTRAK}

Penelitian ini memiliki tujuan untuk menganalisis konsep strategi pemasaran yang paling cocok untuk digunakan Agribisnis Semangka Batam di Kelurahan Pulau Setokok Batam. Penelitian ini menggunakan pendekatan deskriptif kualitatif. Sumber data dalam penelitian ini yaitu data primer dari responden dan sekunder sumber dari dokumen perusahaan, jurnal dan lainnya. Selain itu, teknik observasi, wawancara dan pencatatan juga digunakan untuk mengumpulkan data. Analisis data dalam penelitian 
menggunakan analisis SWOT. Hasil penelitian menunjukkan bahwa dengan menggunakan grafik SWOT untuk analisis diketahui bahwa posisi agribisnis semangka berada pada posisi kuadran I. Ini merupakan posisi agresif, oleh karena itu lebih sesuai menggunakan Strategi Pertumbuhan. Sedangkan, alternatif lain yang sesuai untuk pengembangan bisnis/ usaha Agribisnis Semangka ini menggunakan strategi S-O (Strength-Opportunity) dengan menjaga kualitas buah dan pelayanan pada konsumen, memanfaatkan jalur distribusi, meningkatkan promosi pada tiap jenis produk memanfaatkan peluang pasar yang luas serta mempertahankan harga yang dapat bersaing di pasaran.

Kata Kunci: Analisis SWOT, Strategi Pemasaran, Agribisnis

\section{PENDAHULUAN}

Bidang pertanian terdiri dari beberapa subsektor. Bidang pertanian yang paling dibutuhkan di Indonesia seperti pada sektor tanaman pangan, tanaman hasil perkebunan dan tanaman hortikultura. Sektor agribisnis menjadi salah satu sektor yang memiliki pasar yang unggul. Pola pertanian agribisnis bertujuan untuk menumbuhkembangkan kemandirian pelaku utama dalam melakukan budidaya tanaman (Suparwata \& Djibran, 2018).

Agribisnis semangka sudah tersebar di beberapa negara besar seperti Amerika Serikat, Turki, Iran, Rusia, Brazil, Mesir, Meksiko dan Kazakhstan. Untuk di kawasan Asia sendiri Agribisnis Semangka ini dapat di temukan di negara Indonesia, China, dan India. China saat ini merupakan negara produsen semangka terbesar di dunia (National Watermelon Promotion Board, 2012). Agribisnis semangka di Indonesia sudah banyak tersebar, akan tetapi biaya produksinya cukup besar (Musthofa, Mulyatno, \& Mukson, 2019). Menurut data Badan Pusat Statistik (2015) diketahui bahwa Indonesia memiliki tiga wilayah utama penghasil semangka terbesar yaitu Sumatera Utara, Jawa Timur dan Jawa Tengah.

Tabel 1. Produksi Buah Semangka di Provinsi Kepulauan Riau, 2013 - 2017

\begin{tabular}{ccc}
\hline Provinsi & Tahun & Produksi Semangka Jumlah (Ton) \\
\hline & 2013 & 2014 \\
\cline { 2 - 3 } Kepulauan Riau & 2014 & 2373 \\
\cline { 2 - 3 } & 2015 & 2561 \\
\cline { 2 - 3 } & 2016 & 3341 \\
\cline { 2 - 3 } & 2017 & 4302 \\
\hline
\end{tabular}

Sumber: Badan Pusat Statistik (2017)

Data statistik pada Tabel 1 dari Badan Pusat Statistik produksi semangka di Kepulauan Riau dari beberapa tahun terakhir terus mengalami peningkatan

70 | Fandy Bestario Harlan; Adhitomo Wirawan; Nur Alifia Maulida; Analisis.. 
dalam kurun waktu 7 tahun. Produksi semangka yang dihasilkan oleh provinsi Kepulauan Riau tahun 2013 sebanyak 2014 ton, tahun 2014 sebanyak 2373 ton, tahun 2015 sebanyak 2561 ton, tahun 2016 sebanyak 3341 ton dan tahun 2017 sebanyak 4302 ton.

Berdasarkan data di atas dan berdasarkan hasil survey lapangan kepada para pedagang buah-buahan di Kota Batam, kondisi persaingan pasar di lingkungan usaha agribisnis semangka yang semakin ketat menuntut para pengusaha untuk menerapkan berbagai strategi bisnis agar dapat unggul di persaingan pasar.

Melalui kegiatan pemasaran, produk buah semangka yang dihasilkan oleh produsen dapat sampai ke konsumen akhir. Selain itu, melalui kegiatan pemasaran pula produk buah semangka dari petani dapat terjual dan mampu memberikan keuntungan dari proses jual-beli yang berlangsung.

Maka dari deskripsi di atas dan data yang tersaji di atas, penelitian ini bertujuan untuk menganalisis konsep strategi pemasaran yang dapat diterapkan pada pertanian semangka terintegrasi di Desa Pulau Setokok, Batam.

\section{METODE PENELITIAN}

\section{Desain atau Rancangan Penelitian}

Penelitian ini menggunakan analisis deskriptif kualitatif. Peneliti akan menganalisis formulasi strategi pemasaran yang harus dilakukan pada Agribisnis Semangka dengan objek penelitian Agribisnis Semangka di Pulau Setokok Batam. Penelitian ini dilakukan dengan observasi dan wawancara kepada pemilik usaha dan petani semangka. Selain itu juga dilakukan survey yang dimaksudkan untuk mendata dan menemukan fakta terkini terhadap agribisnis buah semangka (Suparwata \& Pomolango, 2019).

\section{Objek dan Ruang Lingkup Penelitian}

Objek penelitian ini berada di Kelurahan Pulau Setokok, Kota Batam. Penelitian ini difokuskan untuk menemukan formulasi strategi pemasaran yang dapat diterapkan pada Agribisnis Semangka di Kelurahan Pulau Setokok, Kota Batam.

\section{Pemasaran}

Mengutip dari Rangkuti (2015), pemasaran yaitu sebuah kegiatan yang ditentukan oleh faktor-faktor seperti sosial, ekonomi, budaya, politik, dan manajerial akibat adanya pengaruh dari faktor-faktor di atas, seorang individu ataupun kelompok bisa mendapatkan produk yang memiliki nilai. 


\section{Bauran Pemasaran}

Menurut Lupiyoadi (2013), bauran pemasaran merupakan alat bagi pemasar yang memuat berbagai elemen rencana pemasaran yang perlu diperhatikan, agar penerapan strategi pemasaran dan positioning yang telah ditentukan dapat berjalan dengan sukses.

\section{Komunikasi Pemasaran}

Menurut Kotler \& Keller (2009), komunikasi pemasaran adalah sarana perusahaan mencoba untuk berkomunikasi secara langsung atau tidak langsung tentang produk dan merek yang disediakannya, dan merupakan cara untuk membujuk dan mengingatkan konsumen.

\section{Analisa IFAS (Internal Factors Analysis Strategic) dan EFAS (External Factors Analysis Strategic)}

Faktor strategis untuk internal perusahaan dapat diidentifikasi dengan menggunakan tabel IFAS (Internal Factors Analysis Strategic) dan EFAS (External Factors Analysis Strategic). Analisis faktor internal dan faktor eksternal dapat digunakan untuk mengetahui faktor internal apa saja yang dapat mempengaruhi pengembangan usaha baik kelemahan maupun kekuatan. Analisis faktor eksternal digunakan untuk menentukan peluang serta ancaman yang dihadapi perusahaan dalam pengembangan usahanya (Subaktilah, Kuswardani, \& Yuwanti, 2018). Menurut Pertiwi, et al (2016) faktor eksternal yaitu faktor diluar jangkauan perusahaan yang terdiri dari pesaing, teknologi, peraturani pemerintah, keadaan perekonomian, dan lingkungani sosial budaya

\section{Analisis SWOT}

Analisis SWOT merupakan suatu metode untuk mengidentifikasi berbagai faktor secara sistematis untuk merumuskan strategi perusahaan (Rangkuti, 2018). Analisis SWOT telah digunakan pada berbagai bidang dalam pemilihan strategi (Relawati, Baroh, \& Ariadi, 2015). Pada bidang agribisnis, analisis SWOT diantaranya ditemukan pada strategi pengembangan jeruk keprok Soe (Namah \& Sinlae, 2012); strategi pengembangan industri jagung (Wan-rong et al., 2013); dan strategi pengembangan agribisnis (Darmansyah, Rochana, Sutardi, \& Zuraida, 2014). Analisis ini dilakukan dengan menerapkan kriteria kesesuaian dengan data kuantitatif dan deskripsi (Muhammad, 2018). 


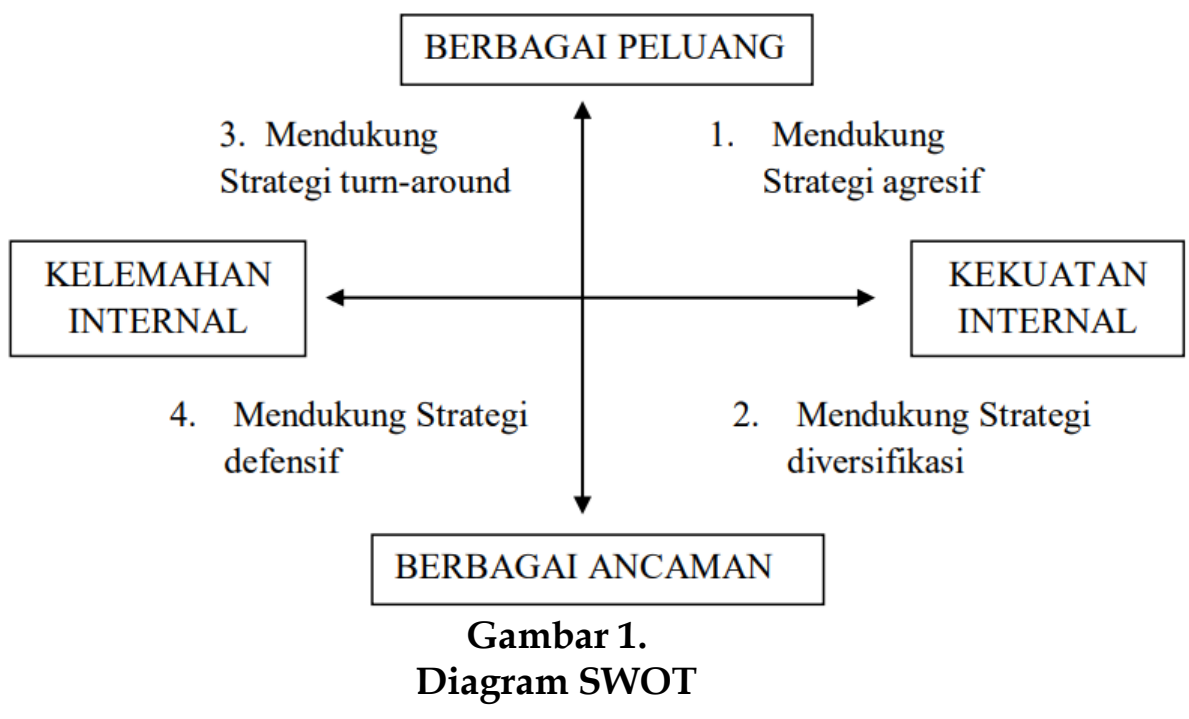

\section{Matriks SWOT}

Metode SWOT sering digunakan untuk melakukan analisis lingkungan karena metode ini merupakan metode sederhana dalam merumuskan strategistrategi (Kurniawan \& Haryati, 2017). Menurut (David, 1999), SWOT adalah sebuah alat penentuan untuk membantu mengembangkan empat strategi: SO (Strength Opportunities), WO (Weakness Opportunities), ST (Strength Threat), WT (Weakness Threat). Peluang dan ancaman yang dihadapi perusahaan dapat terlihat dari matriks SWOT. Empat alternatif strategis yang dihasilkan oleh matriks SWOT adalah sebagai berikut.

a. Strategi S-O

Menggunakan seluruh kekuatan perusahaan yang ada agar dapat mengambil dan memanfaatkan peluang yang ada sebesar-besarnya.

b. Strategi S-T

Memanfaatkan kekuatan yang ada pada perusahaan untuk menghindari adanya ancaman yang datang.

c. Strategi W-O

Memanfaatkan peluang yang ada dan mengurangi kelemahan yang ada di perusahaan.

d. Strategi W-T

Fokus pada usaha defensif dan mencoba mengurangi kelemahan di perusahaan untuk terhindar dari ancaman. 


\section{HASIL DAN PEMBAHASAN}

\section{Gambaran Umum}

Agribisnis yang menjadi objek penelitian penulis merupakan komoditas semangka yang dimiliki Bapak Djupri. Sebelum menggeluti komoditas semangka, Bapak Djupri telah memiliki pengalaman di bidang pertanian selama 3 tahun yaitu diawali pada tahun 2007 hingga tahun 2010. Jenis komoditas yang di kelola saat itu adalah sayur-sayuran berupa jagung, kangkung, bayam, selada, ubi, mentimun, cabai merah, cabai hijau, cabai rawit, kacang panjang, dan sebagainya. Usaha agribisnis semangka ini masih terbilang cukup baru, dimana usaha ini dimulai pada bulan Desember 2018 dan berlokasi di Barelang, Kelurahan Pulau Setokok, Kota Batam. Buah semangka dipilih Bapak Djupri karena peluang usaha yang cukup bagus. Menurut survey, petani semangka sendiri masih tergolong sedikit sedangkan permintaan semangka di pasar cukup tinggi.

\section{Konsep Strategi Pemasaran}

\section{Strategi Persaingan}

\section{Segmenting (Segmentasi)}

Dalam hal ini, segmentasi konsumen untuk produk buah semangka mencakup seluruh lapisan masyarakat Kota Batam dan sekitarnya.

\section{Targeting (Sasaran)}

Sasaran target pasar untuk komoditas semangka sendiri masih cukup luas. Target pasar Agribisnis Semangka sendiri merupakan seluruh pedagang buah-buahan yang ada di Kota Batam.

\section{Positioning (Penentuan Posisi)}

Positioning yang ingin dibagun yaitu dalam hal kualitas dan pelayanan yang baik dengan melayani pesanan sebaik mungkin sesuai standar yang ditetapkan.

\section{Bauran Pemasaran}

\section{Product (Produk)}

Perencanaan strategi produk pada Agribisnis Semangka ini yaitu tetap menggunakan bahan-bahan baku yang memiliki kualitas dan telah terjamin agar dapat terus menjaga kepuasan dan kepercayaan konsumen. 


\section{Place (Tempat dan Distribusi)}

Lokasi pertanian Agribisnis Semangka yang bertempat di Jembatan 3 Barelang ini cukup mudah dijangkau konsumen sehingga tidak memerlukan strategi dalam pemilihan tempat.

\section{Price (Harga)}

Harga yang ditetapkan pemasok buah semangka sendiri cukup variatif. Jika buah semangka sedang membanjiri pasaran maka harga jual buah Rp 4.000 - Rp 5.000 sedangkan jika buah semangka sedang langka di pasaran maka harga jual buah hingga Rp 5.000 - Rp 6.000. Karena harga yang ditetapkan sudah bersaing dengan harga pasar, maka tidak diperlukan perencanaan tambahan dalam penetapan harga.

\section{Promotion (Promosi)}

Berdasarkan data yang diperoleh, promosi yang dilakukan selama ini hanya dari mulut ke mulut saja. Padahal di era teknologi yang berkembang saat ini, pemanfaatan media sosial sangat efektif misalnya; Facebook, Youtube dan Instagram.

\section{Komunikasi Pemasaran}

Rancangan komunikasi pemasaran untuk Agribisnis Semangka ini yaitu:

\section{Promosi Penjualan}

Rancangan promosi penjualan pada Agribisnis Semangka ini berupa pemberian potongan harga atau diskon untuk pelanggan tetap dan pelanggan akhir yang membeli semangka dalam jumlah banyak.

\section{Penjualan Personal}

Rancangan penjualan personal untuk Agribisnis Semangka ini bisa dilakukan dengan mendatangi secara langsung ke tempat-tempat agen atau pedagang buah-buahan yang tersebar di Kota Batam.

\section{Pemasaran Online}

Rancangan pemasaran online untuk Agribisnis Semangka ini menggunakan sarana promosi melalui platform media sosial, contohnya menggunakan Facebook Ads (Facebook), Instagram, dan Youtube.

\section{Matriks IFAS dan EFAS}

Dilihat dari Tabel IFAS, skor untuk faktor kekuatan di bisnis ini dan kelemahan di bisnis ini yaitu totalnya 3,02. Nilai skor kekuatan internal lebih 
dari 2,5 yang menandakan kondisi internal perusahaan yang baik dan kuat. Sedangkan dilihat dari hasil pada Tabel EFAS, nilai total skor untuk faktor peluang di bisnis ini dan ancaman di bisnis ini yaitu 3,27 yang mengidentifikasikan bahwa perusahaan mampu menangkap peluang dengan cara yang sangat baik dan mampu menghindar dari ancaman-ancaman yang ada di industri tersebut.

\section{Diagram SWOT}

Berdasarkan analisis tabel maka masing-masing nilai skor kekuatan, kelemahan, peluang dan ancaman yaitu:

1. Skor Kekuatan $=2,46$

2. Skor Kelemahan $=0,56$

3. Skor Peluang $=1,94$

4. Skor Ancaman $=1,33$

Berdasarkan data diatas, diketahui bahwa skor kekuatan memiliki nilai yang lebih besar daripada skor kelemahan yaitu selisihnya (+) 1,90 dan skor peluang memiliki nilai yang lebih besar daripada skor ancaman yaitu dengan selisih $(+) 0,61$.

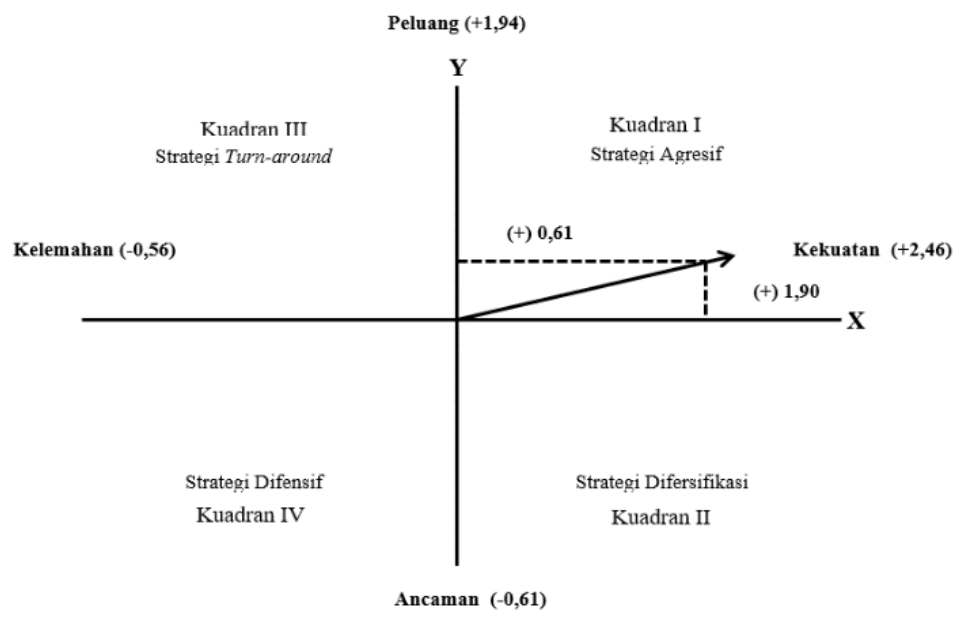

Gambar 2.

\section{Diagram SWOT Agribisnis Semangka}

Berdasarkan analisa faktor internal dan eksternal menunjukkan bahwa Agribisnis Semangka berada pada posisi kuadran I. Berada pada kuadran I berarti posisi yang cukup menguntungkan untuk perusahaan dan dapat menerapkan strategi pertumbuhan agresif di pasaran (Growth Oriented Strategy).

Dengan demikian, Agribisnis Semangka memiliki kekuatan maupun peluang yang lebih besar dibandingkan kelemahan maupun ancamannya. 
Sehingga, setiap kekuatan dan peluang bisa dimaksimalkan untuk peningkatan di Agribisnis Semangka.

\section{Matriks SWOT}

Strengths, Weaknesses, Opportunities and Threats (SWOT) Analysis merupakan analisis yang mengintegrasikan antara kondisi internal dan eksternal yang mempengaruhi kinerja organisasi (Erniati, Solahudin, Lulung, \& Wardani, 2020). Kombinasi dari dua faktor di atas akan dijelaskan pada matriks SWOT.

\section{Tabel 1 Matriks SWOT}

\begin{tabular}{|c|c|c|}
\hline EFAS IFAS & Kekuatan (Strength) & Kelemahan (Weakness) \\
\hline $\begin{array}{r}\text { Peluang } \\
\text { (Opportunity) }\end{array}$ & $\begin{array}{l}\text { Strategi S-O } \\
\text { 1. Menjaga kualitas buah. } \\
\text { 2. Memanfaatkan jalur distribusi } \\
\text { yang mudah dan lancar. } \\
\text { 3. Meningkatkan promosi pada } \\
\text { tiap jenis produk yang beraneka } \\
\text { ragam dengan memanfaatkan } \\
\text { peluang pasar yang luas. } \\
\text { 4. Mempertahankan harga yang } \\
\text { dapat bersaing di pasaran. } \\
\text { 5. Menjaga kualitas pelayanan } \\
\text { yang baik untuk konsumen. }\end{array}$ & $\begin{array}{l}\text { Strategi W-O } \\
\text { 1. Membuat perencanaan strategi } \\
\text { promosi dengan analisis segmen } \\
\text { pasar yang akan dituju } \\
\text { kedepannya. } \\
\text { 2. Memberikan petunjuk jalan atau } \\
\text { denah lokasi perkebunan,agar } \\
\text { mudah ditemukan konsumen. } \\
\text { 3. Membeli mobil untuk mengurangi } \\
\text { biaya sewa sehingga jasa } \\
\text { penghantaran produk tetap } \\
\text { dijalankan untuk memuaskan } \\
\text { pelayanan konsumen. } \\
\text { 4. Menjaga persediaan bahan baku } \\
\text { penanaman untuk mengantisipasi } \\
\text { kondisi ekonomi. }\end{array}$ \\
\hline $\begin{array}{l}\text { Ancaman } \\
\text { (Threats) }\end{array}$ & $\begin{array}{l}\text { Strategi S-T } \\
\text { 1. Harga penjualan yang tetap } \\
\text { lebih murah dibandingkan } \\
\text { pesaing } \\
\text { 2. Mengatur jadwal penanaman } \\
\text { berkala agar dapat } \\
\text { menyeimbangi persediaan buah } \\
\text { semangka dan menghindari } \\
\text { banjirnya buah di pasar. } \\
\text { 3. Melakukan upaya perawatan } \\
\text { dan pemeliharaan semaksimal } \\
\text { mungkin agar kualitas buah } \\
\text { terjaga. }\end{array}$ & $\begin{array}{l}\text { Strategi W-T } \\
\text { 1. Mempertahankan hubungan baik } \\
\text { dengan pelanggan. } \\
\text { 2. Mengikuti dan bergabung dalam } \\
\text { kegiatan sosial dan acara. } \\
\text { 3. Mengembangkan dan } \\
\text { meningkatkan kualitas pelayanan } \\
\text { pada konsumen. } \\
\text { 4. Mempelajari dunia usaha dan } \\
\text { perkembangannya. }\end{array}$ \\
\hline
\end{tabular}




\section{SIMPULAN DAN SARAN}

\section{Simpulan}

Kesimpulan pada penelitian ini yaitu pada matriks IFAS, nilai skor faktor kekuatan dan faktor kelemahan yaitu 3,02, faktor kekuatan dan kelemahan Agribisnis Semangka berada pada posisi internal yang begitu kuat. Pada matriks EFAS, faktor peluang dan ancaman memiliki total skor 3,27 yang berarti Agribisnis Semangka tersebut dapat memanfaatkan dengan baik peluang yang ada dan dapat bertahan dari ancaman di pasar industrinya.

Agribisnis Semangka berada pada kuadran Growth dimana usaha ini mempunyai peluang untuk dapat memanfaatkan teknologi guna memaksimalkan promosi untuk menambah pelanggan. Selain itu, meningkatkan produksi yang efektif dan mempertahankan kualitas-kualitas buah. Sedangkan pada strategi bauran pemasaran, perlu adanya pengembangan atau perubahan pada 2 (dua) strategi yaitu pada strategi Produk (Product) dan Promosi (Promotion).

Strategi Komunikasi Pemasaran yang disusun yaitu: Promosi Penjualan, berupa pemberian potongan harga untuk pelanggan tetap. Penjualan Personal, dengan mendatangi secara langsung agen atau pedagang buah.. Selain itu, melakukan pemasaran online melalui media sosial.

Alternatif starategi yang dapat diterapkan diantaranya, menjaga kualitas buah dengan melakukan upaya perawatan dan pemeliharan, mempertahankan hubungan baik dengan meningkatkan kualitas pelayanan, mempertahankan harga yang dapat bersaing di pasaran, mengatur jadwal penanaman berkala agar dapat menyeimbangi persediaan buah semangka dan menghindari banjirnya buah di pasar, menciptakan dan meningkatkan perencanaan strategi promosi dengan dengan memanfaatkan peluang pasar yang luas, memberikan petunjuk jalan atau denah lokasi perkebunan, membeli mobil sebagai aset usaha, menjaga persediaan bahan baku penanaman untuk mengantisipasi kondisi ekonomi.

\section{Saran}

Saran yang dapat diberikan untuk pengusaha maupun untuk kebutuhan penelitian ke depannya adalah sebagai berikut:

\section{Bagi Pengusaha}

a. Peningkatan kualitas produk dan menggunakan logo pada produk agar mudah dikenal masyarakat.

b. Meningkatkan promosi khususnya melalui media online untuk memperluas target pasar 


\section{Bagi Penelitian Selanjutnya}

Menambah atau mengganti metode penelitian menggunakan metodemetode lainnya seperti penggunaan metode:

\section{Metode Business Model Canvas}

Metode ini mengacu pada pertanyaan kuesioner maupun wawancara yang disiapkan untuk diberikan kepada responden. Pertanyaan kuesioner atau wawancara tersebut mewakili 9 elemen yang terdapat pada BMC.

\section{Metode pemasaran relasional}

Pembahasan mengenai hubungan enam pasar domain yang terdiri dari: Pasar Pelanggan, Pasar Pemasok dan pasar aliansi, Pasar Pengaruh, Pasar Internal, Pasar Rujukan, Pasar Rekrutmen.

\section{DAFTAR PUSTAKA}

Badan Pusat Statistik Jakarta Pusat, 2015. Statistik Tanaman Sayuran dan BuahBuahan Semusim. Jakarta Pusat: Badan Pusat Statistik

Badan Pusat Statistik Provinsi Kepulauan Riau , 2017. Produksi Tanaman Buahbuahan dan Sayuran Tahunan (Kuintal). Kepulauan Riau : Badan Pusat Statistik

Darmansyah, A., Rochana, S. H., Sutardi, A., \& Zuraida, U. (2014). The New Growth Centres and Strategy for Building and Accelerating Agribusiness Development in Cirebon Regency, Indonesia. Procedia Social and Behavioral Sciences, 115(Iicies 2013), 296-304. doi:10.1016/j.sbspro. 2014.02.437

David, F. R. (1999). Strategic Management: Concepts and Cases. Prentice Hall. Erniati, Solahudin, M., Lulung, P., \& Wardani, I. K. (2020). Aplikasi Metode Analisis Swot Untuk Merumuskan Strategi Pemanfaatan Mekanisasi Pertanian di Kabupaten Kapuas Hulu Provinsi Kalimantan Barat. JRPB, 219-229.

Kotler, P., \& Keller, K. L. (2009). Manajemen Pemasaran (2 ed.). (A. Maulana, Y.

S. Hayati, Penyunt., \& B. Sabran, Penerj.) Jakarta, Indonesia: Erlangga.

Kurniawan, M., \& Haryati, N. (2017). Analisis Strategi Pengembangan Usaha

Minuman Sari Buah Sirsak. Jurnal Teknologi dan Manajemen Agroindustri, 97-102.

Lupiyoadi, R. (2013). Manajemen Pemasaran Jasa: Berbasis Kompetensi (3 ed.). Jakarta, Indonesia: Salemba Empat.

Muhammad, M. (2018). Analisis SWOT sebagai Strategi Pengembangan Usahatani Buah Naga Merah (Hylocereus costaricensis) Kecamatan 
Wasile Timur Kabupaten Halmahera Timur . Jurnal Agribisnis Perikanan, 28-37.

Musthofa, A. M., Mulyatno, B., \& Mukson. (2019). Analisis Strategi Pemasaran Buah Semangka di Gabungan Kelompok Tani (Gapoktan) Tani Makmur di Desa Cabean Kecamatan Demak Kabupaten Demak. Jurnal Hexagro, 1-10.

Namah, C. N., \& Sinlae, D. V. (2012). The Feasibility Study of Keprok SoE Citrus Farming and the Development Strategis of Local Citrus Farming. Procedia Economics and Finance, 4(Icsmed), 86- 96. doi:10.1016/S22125671(12)00324-3

National Watermelon Promotion Board. (2012). Watermelon Board. Dipetik Januari 5, 2019, dari Watermelon.org https://www.watermelon.org/Watermelon-101

Pertiwi, M, I, Edy, Y dan Sunarti. (2016). Pengaruh Bauran Pemasaran Terhadap Keputusan Pembelian (Survei Pada Konsumen Baker's King Donuts dan Coffee Di Mx Mall Malang). J Administrasi Bisnis 37(1): 179-186.

Rangkuti, F. (2015). Analisis SWOT: Teknik Membedah Kasus Bisnis (20 ed.). Jakarta: PT. Gramedia Pustaka Utama.

Rangkuti, R. (2018). Analisis Strategi Pemasaran Dalam Meningkatkan Volume Penjualan Produk Rotan Studi Pada UD. Mula Rotan Petisah Kota Medan. Administrasi Bisnis.

Relawati, R., Baroh, I., \& Ariadi, B. Y. (2015). Analisis Swot Untuk Pengembangan Strategi Pemasaran Produk Olahan Apel di Malang Raya. Jurnal Sosial Ekonomi Pertanian dan Agribisnis, 58-69.

Subaktilah, Y., Kuswardani, N., \& Yuwanti, S. (2018). Analisis Swot: Faktor Internal Dan Eksternal Pada Pengembangan Usaha Gula Merah Tebu (Studi Kasus di UKM Bumi Asih, Kabupaten Bondowoso). Jurnal Agroteknologi, 107-115.

Suparwata, D. O., \& Djibran, M. (2018). Pemanfaatan Pekarangan Bero Untuk Usahatani Buah Naga. Journal Of Agritech Science (JASC), 72-89.

Suparwata, D. O., \& Pomolango, R. (2019). Arahan Pengembangan Agribisnis Buah Naga di Pekarangan Terintegrasi Desa Wisata Banuroja. Jurnal Ilmiah Fakultas Pertanian, 85-99.

Wan-rong, G., Yi, J., Yao, M., Jian-guo, W., Xian-long, Z., Jing, L., \& Shi, W. (2013). SWOT Analysis and Development Strategies of Maize Industry in Heilongjiang Province. Journal of Northeast Agricultural University, 20(1), 76-84. doi:10.1016/S1006-8104(13)60013-6

80 | Fandy Bestario Harlan; Adhitomo Wirawan; Nur Alifia Maulida; Analisis.. 